\title{
La teoría scheleriana de la identidad personal y su matriz romántica
}

Scheler's theory of personal identity and its Romantic origin

\author{
LEONARDO RoDRÍGUEZ DUPLÁ \\ Universidad Complutense de Madrid \\ Facultad de Filosofía \\ Departamento de Historia de la Filosofía, Estética y Filosofía Moral \\ 28040 Madrid (España) \\ leonrodr@ucm.es
}

\begin{abstract}
The aim of this paper is to expound the precise meaning and the systematic coherence of one of the most important tenets of Max Scheler's philosophical anthropology: his claim that every human being, as a spiritual being, has an "individual value-essence“ that makes him different from any other human being. The last section of the paper traces the Romantic origin of this aspect of Scheler's anthropology.
\end{abstract}

Keywords: Scheler, individual essence, ordo amoris, value, Romanticism.
Resumen: El propósito de este trabajo es exponer el sentido preciso y la coherencia sistemática de una de las tesis más importantes de la antropología filosófica de Max Scheler: la que afirma que cada hombre, en tanto que ser espiritual, posee una „esencia individual de valor" que lo distingue de todos los demás seres humanos. En el último apartado del trabajo se muestra la raíz romántica de este aspecto de la antropología scheleriana.

Palabras clave: Scheler, esencia individual, ordo amoris, valor, Romanticismo. 


\section{LA ESENCIA INDIVIDUAL DE VALOR COMO CONSTITUTIVO}

DE LA IDENTIDAD PERSONAL

U na de las tesis más importantes y características de la antropología de Scheler es la que sostiene que cada hombre, en tanto que ser espiritual, posee una "esencia individual" que lo distingue de todos los demás seres humanos. En esta esencia individual, creada por Dios, estribaría propiamente su identidad personal. Con esta tesis Scheler se sitúa, desde luego, muy lejos de las concepciones materialistas del hombre, que ni siquiera le reconocen una dimensión espiritual, pero también se desmarca de aquellas teorías clásicas que, sin ser materialistas, sitúan el principium individuationis del ser humano en un nivel distinto del espiritual.

Entre las concepciones clásicas rechazadas por Scheler se cuenta, por ejemplo, la de Averroes, que concibe el espíritu humano como único y común a toda la especie, pero capaz de vincularse a múltiples cuerpos, y hace precisamente de la vinculación a un cuerpo determinado el factor responsable de la individualidad de cada hombre. Frente a esta explicación, adoptada luego por autores como Spinoza o Von Hartmann, el filósofo de Múnich insistirá en que el ser humano es un individuo único e irrepetible ya en tanto que ser espiritual-personal, abstracción hecha por tanto de su posesión de un cuerpo ${ }^{1}$. Por este mismo motivo también considera insuficiente la doctrina tomista que hace de la materia signata quantitate el principio de individuación. A su juicio, dicha doctrina podría explicar a lo sumo la singularidad del hombre como persona (es decir, su diferencia numérica respecto de cualquier otra persona),

1. Quizá no esté de más recordar algo en lo que Scheler insiste a menudo: las doctrinas metafísicas que conciben el yo individual como mero aspecto o manifestación parcial de una realidad espiritual única son incompatibles con el sentido evidente de experiencias tan decisivas como el amor o la compasión, las cuales presuponen justamente la diversidad existencial de los sujetos entre los que estas experiencias tienen lugar. El amor a que se acaba de hacer referencia es el amor espiritual. En cambio, sin tomamos como guía de nuestra indagación metafísica el amor vital, llegaremos a conclusiones muy distintas. En efecto, ciertas experiencias de este ámbito sugieren vivamente la unidad fundamental de toda forma de vida cósmica. Cf. L. Rodríguez Duplá, Las ideas biológicas de Max Scheler, "Daimon" 7 (2012) 97-115. 
pero no su individualidad en sentido estricto; para explicar esta última sería preciso recurrir a un principio diferenciador situado en la propia esfera espiritual (como lo es la esencia individual postulada por Scheler) y no fuera de ella.

En cuanto a la concepción kantiana de la persona, Scheler sostiene que en el fondo está emparentada con la de Averroes, y adolece por tanto de sus mismos defectos. Para ver que es así, basta con tener presente que Kant reduce la esfera espiritual a la razón pura, la cual es, no menos que el intelecto agente de Averroes, una facultad supraindividual. Para Kant ser personal es lo mismo que ser racional. La persona concreta es concebida aquí como una mera X, como sujeto lógico o punto de partida de una actividad racional. El problema está en explicar qué es eso de una "persona concreta", es decir, qué distingue una $\mathrm{X}$ de otra. Para contestar a esta pregunta Kant recurre al contenido empírico de las vivencias, que es distinto para cada sujeto. Como se ve, también en esta posición el principio de individuación es situado fuera de la esfera personal. Más aún, se da la paradoja de que a más individualidad, menos personalidad, pues lo que hace de un individuo humano este individuo concreto son ciertos hechos empíricos que se amalgaman con su condición personal y, al no ser ellos mismos de orden racional, la enturbian o adulteran. Como dice Scheler agudamente, de este planteamiento no se sigue la autonomía de la persona, sino la más extrema "logonomía"

Marcadas las distancias entre la posición de Scheler y otras doctrinas clásicas acerca de la identidad personal, debemos precisar en qué consiste la esencia individual postulada por aquél. Scheler sostiene que la esencia individual que confiere a cada ser humano su identidad espiritual es una "esencia de valor" (Wertwesen). Podemos decir también que, según nuestro filósofo, la identidad de cada persona consiste a última hora en que su espíritu posee en exclusiva un determinado perfil axiológico. Para entender el sentido de esta tesis, conviene que la consideremos en perspectiva sistemática, exponiendo cómo encaja la idea de una esencia

2. GW2, 372. Citaremos siempre a SCHELER por los Gesammelte Werke, editados por M. SCHELER y M. FrINGS, con indicación de volumen y página. 
individual de valor con otras piezas teóricas fundamentales de la antropología scheleriana.

Recordemos en primer lugar que Scheler define a la persona como unidad (inmediatamente vivida) de actos de distintas especies ${ }^{3}$. Un ser consciente que fuera capaz únicamente de un tipo de actos (sólo teóricos, por ejemplo, o sólo volitivos) no sería persona, sino tan sólo sujeto (lógico) de esos actos homogéneos. Recordemos también que entre las distintas especies de actos propios del ser personal existen, según nuestro filósofo, relaciones esenciales de fundación. Los actos más básicos, los que constituyen el suelo sobre el que se levanta todo otro acto, son de naturaleza emocional. Según esto, el estrato más profundo de la subjetividad estaría hecho de sentimientos. Y si, guiados por Scheler, dirigimos la mirada fenomenológica a ese nivel emocional básico, verdadero humus de la personalidad, descubriremos que su capa más profunda la forman los actos de amor. Esto explica que Scheler afirmara, en un ensayo famoso ${ }^{5}$, que el ser humano es ante todo un "ordo amoris", vale decir: un sistema de íntimas adhesiones cordiales. ¿Adhesiones a qué? Con esta pregunta se cierra el círculo que estamos trazando, pues el amor es entendido en el marco de esta teoría como una vivencia intencional dirigida al mundo de los valores; pero no a ese mundo en su totalidad inagotable, sino a una determinada constelación de valores que se recorta sobre ese trasfondo genérico. La identidad de cada persona consistiría en su estar orientada, ya en su estrato más profundo, a una determinada escala de valores. Esta naturaleza intencional del amor explica que, cuando se trata de indicar el constituido último de la identidad personal, Scheler hable unas veces de un ordo amoris y otras de una esencia de valor; es claro que en el primer caso se refiere al acto básico del ser personal y en el segundo al objeto de ese acto, de modo que se trata en realidad de dos maneras equivalentes de formular una misma tesis.

\footnotetext{
3. Cf. $G W 2,371$ y 382 .

4. Sería impreciso decir que esa capa última la forman actos de amor y de odio, pues el odio es, a juicio de Scheler, una vivencia fundada (cf. $G W 10,369$ s.) y buscamos lo fundante, no lo fundado.

5. Nos referimos al ensayo inacabado Ordo amoris ( $G W 10,345-376)$, del que nos ocuparemos en los dos siguientes apartados.
} 


\section{EL ORDO AMORIS EN SENTIDO DESCRIPTIVO}

Los textos más importantes para el estudio de la teoría scheleriana de la esencia individual de valor son el ya citado ensayo "Ordo amoris", que quedó incompleto y fue publicado póstumamente, y las páginas dedicadas a esta cuestión en la sección sexta de Formalismo ${ }^{6}$, en la que el filósofo expone su teoría de la persona. Entre uno y otro texto existen algunas diferencias terminológicas: en el primero apenas se utiliza la expresión "esencia de valor" para referirse al constitutivo último de la identidad personal, sino que se habla casi siempre del "ordo amoris" de la persona, o también de su "determinación individual" (individuelle Bestimmung). Sin embargo, la comparación de los textos permite comprobar que todas esas expresiones son equivalentes. Esto se pone de manifiesto cuando Scheler define la determinación individual como "una esencia de valor (Wertwesenbeit) intemporal en sí en la forma de la personalidad"7. O cuando, al comienzo del citado ensayo, enuncia su conocida tesis:

Quien tiene el ordo amoris de un hombre, tiene al hombre. Tiene para él como sujeto moral lo que la fórmula cristalina es para el cristal. Penetra con la mirada en el hombre todo lo que se puede penetrar en un hombre. Contempla, por detrás de toda la multiplicidad y complejidad empírica, las líneas fundamentales que de modo constante y simple recorren su ánimo $[\text { Gemüt }]^{8}$, el cual merece —-más que el conocer y el querer- ser considerado el núcleo del hombre como ser espiritual. Posee en un esquema espiritual la fuente original que alimenta secretamente todo lo que sale de este hombre $[\ldots]^{9}$.

Pero la tesis de la equivalencia de todos esos términos tiene que ser precisada, habida cuenta de que Scheler distingue al comienzo de su

6. Cf. $G W 2,469-486$.

7. $G W 10,353$.

8. La expresión "ánimo" se refiere aquí a la esfera afectiva del ser personal. Más adelante emplea también en el mismo sentido el término "corazón” (Cf. GW 10, 361).

9. $G W 10,348$. 
ensayo hasta tres sentidos diferentes de la expresión "ordo amoris". Debemos aclarar, por tanto, en cuál de las tres acepciones equivale "ordo amoris" a "esencia individual de valor" y a "determinación individual".

Scheler distingue entre ordo amoris en sentido normativo y en sentido descriptivo. El primero se define por la escala de valores a la que está abierto el estrato más profundo de la personalidad; esta escala es limitada - no agota la inmensa riqueza del mundo de los valores-, es distinta para cada hombre y es de hecho lo que le confiere su irrepetible identidad personal. El ordo amoris normativo equivale, por tanto, a la esencia de valor individual.

A su vez, el ordo amoris descriptivo se define por la escala de valores que de hecho se orienta la vida personal de un hombre, y que puede coincidir o no con la escala propia de su ordo amoris normativo. En efecto, el hombre puede ser infiel a sí mismo, poner su corazón en valores distintos de los que hacen de él este hombre. Scheler dirá que cuando esto sucede el hombre vuelve la espalda a su verdadera "vocación", a la intransferible "tarea" moral a la que Dios lo había llamado al crearlo de acuerdo con una determinada idea de valor. En cambio, el hombre cuyo ordo amoris descriptivo coincide con el normativo, el hombre fiel a su determinación individual, cumple el precepto de Píndaro, "sé el que eres", y ocupa con ello el lugar que tiene asignado en el plan salvífico de Dios.

A estos dos sentidos principales del ordo amoris se añade todavía un tercero, al que Scheler se refiere muy brevemente, pues no constituye el objeto principal de su ensayo. Ya no se trata de la particular escala de valores a la que responde o debería responder el amor de una persona determinada, sino del orden jerarquizado de los valores objetivos en su totalidad, es decir, la escala omniabarcante de la que están tomadas aquellas escalas particulares. Sólo Dios, amor infinito, conoce plenamente este ordo amoris universal; los hombres, en cambio, acceden a él sólo parcialmente, en la medida en que lo permiten sus respectivas determinaciones individuales, y tienen como tarea colectiva el descubrimiento gradual de nuevos ámbitos de valor en el curso de la historia. Lo que así van descubriendo es "la esfera de 
hechos más objetiva y fundamental que existe"10, por lo que Scheler llegará a afirmar que el ordo amoris, tomado en esta tercera acepción, es "el núcleo del orden del mundo en tanto que orden divino"11.

En el presente trabajo nos vamos a ocupar sobre todo del ordo amoris en sentido normativo. Pero antes convendrá que prestemos atención, en el resto de este apartado, al ordo amoris descriptivo (o fáctico).

La función desempeñada por el ordo amoris fáctico es apuntada por Scheler ya en las primeras líneas de su ensayo:

Sé que tanto los objetos que llego a conocer perceptiva o intelectualmente, como todo lo que quiero, elijo, hago, realizo o efectúo, es dependiente del juego del movimiento de mi corazón ${ }^{12}$.

Es claro que con estas palabras iniciales el filósofo quiere situarnos de inmediato, a bocajarro, ante su tesis de la primacía del amor, la cual es desarrollada en distintas direcciones a lo largo de todo el texto, por desgracia incompleto. La tesis se precisa de un modo interesante cuando, poco después, se afirma que el ordo amoris de un hombre es

la fuente originaria que alimenta secretamente todo lo que procede de este hombre; más aún: lo que determina originariamente lo que continuamente hace ademán de instalarse a su alrededor: en el espacio su entorno moral, y en el tiempo su destino, es decir, la suma de lo posible que le puede pasar a él y sólo a él puede pasarle ${ }^{13}$.

Detengámonos un momento en los conceptos de entorno moral y destino. El término "entorno" (Umwelt) suele ser empleado por Scheler para designar el mundo al que se abre el hombre en tanto

10. $G W 10,362$.

11. $G W 10,356$.

12. $G W 10,347$.

13. $G W 2,348$. 
que ser vivo, pero en las líneas transcritas ese término cobra un sentido distinto, como se hace patente por la presencia del adjetivo "moral". El entorno del ser vivo viene determinado por la estructura axiológica de su nivel pulsional, y explica la acomodación de cada especie de seres vivos a su correspondiente nicho ecológico; son las necesidades de la vida, por tanto, las que determinan el entorno biológico ${ }^{14}$. En cambio, al hablar de entorno moral Scheler se refiere al mundo circundante al que se abre el hombre en tanto que ser espiritual. También este mundo está predeterminado axiológicamente -ésta es precisamente la tesis-, pero los valores que lo estructuran no están dados en el nivel pulsional, sino en el amor espiritual que constituye el fondo de la personalidad. Mientras el entorno biológico es correlativo al cuerpo (Leib), el entorno moral es propio de la persona ${ }^{15}$.

Por su parte, el concepto de destino (Schicksal) sirve para destacar el hecho de que la predeterminación axiológica del mundo personal no tiene únicamente el carácter espacial sugerido por el uso de la palabra "entorno", sino que tiene también una dimensión temporal. El mundo no sólo rodea a la persona, sino que la acompaña a

14. Esta teoría es expuesta en la sección tercera de Formalismo (cf. esp. GW 2, 153172) y constituye la base de la teoría pragmatista de la percepción externa desarrollada por Scheler en Conocimiento y trabajo (cf. esp. $G W 8,315-343$ ).

15. Las vacilaciones terminológicas y conceptuales del texto reflejan un estadio primitivo en el proceso de elaboración por Scheler de su teoría del ordo amoris. En general, hemos de leer este texto embrionario a la luz de las versiones maduras de la misma teoría (es decir, hemos de leer "Ordo amoris" a la luz de las secciones tercera y sexta de Formalismo), pues sólo así se deshacen ciertos equívocos. El más grave procede de que en las primeras páginas del texto que estamos estudiando no se distingue suficientemente lo vital de lo personal. Esta confusión se manifiesta ya en el uso inesperado de "entorno" (unas veces Umwelt, otras Milieu) para referirse a hechos del ámbito personal, y llega a su colmo cuando Scheler afirma que el destino y el entorno se desarrollan "a partir de procesos teleológicos (...) del sujeto psicovital" $(G W 10,353)$, cuando es claro que ha de tratarse de fenómenos de orden espiritual. La crítica no ha solido percatarse de este problema; cf. por ejemplo, A. SANDERS, Max Scheler zur Einfübrung (Junius Verlag, Hamburg, 2001) 64.

Por cierto que de aquí se sigue una importante consecuencia para la datación del texto. Maria Scheler, su primera editora, sitúa su composición en 1916. A nuestro juicio, la comparación con la sección tercera de Formalismo, que vio la luz en 1913, obliga a retrotraer varios años la fecha de composición de "Ordo amoris". 
lo largo de su vida. Ocurre, en efecto, que miramos el mundo a través de las lentes de nuestro ordo amoris, de suerte que los valores que constituyen el polo objetivo de ese amor actúan como mecanismo de selección de las personas y cosas, de los objetos y resistencias que nos salen al paso; y como esas lentes no cambian a cada momento sino que son la condición constante de nuestro acceso a la realidad, no es de extrañar que los hechos y experiencias que se suceden a lo largo de nuestra vida tengan todos un marcado aire de familia. Por supuesto, las vidas de los hombres se asemejarán más o menos, en la medida en que sean semejantes las escalas de valores a las que se dirige su amor fundamental, el amor que ellos son; pero también existen en ese nivel, como sabemos, diferencias irreductibles que otorgan a cada hombre su identidad personal. Ésta es la razón por la que existe una porción de nuestra vida, un conjunto de experiencias, por lo común muchas veces repetidas, que constituyen el destino individual: lo que un hombre no ha buscado ni previsto, pero que sólo a él podía pasarle. Hay un hilo invisible que enhebra los acontecimientos de la vida del individuo, un hilo que no comparte enteramente con nadie: su "genio y figura", su destino ${ }^{16}$.

En los párrafos anteriores nos hemos referido al modo como el ordo amoris configura el entorno moral y el destino del hombre. Debemos insistir en que, al exponer esta doctrina, Scheler está pensando en todo momento en el ordo amoris fáctico, es decir: en lo que a un hombre de hecho le importa y en la medida en que le importa. Precisamente por eso la doctrina scheleriana del destino no tiene connotaciones fatalistas. Scheler no afirma que el futuro esté escrito, sino que se escribirá dentro del margen de maniobra que admita la estructura de valor del ordo amoris fáctico de cada hombre; es dentro de ese margen donde opera habitualmente la libertad individual. E incluso hay un uso más radical de la libertad que permite influir en alguna medida en ese ordo amoris. Scheler ha ilustrado esto con su análisis del fenómeno del arrepentimiento, merced al cual el hom-

16. Cf. E. Nelly, Der Begriff des Schicksals im Denken Max Schelers, en C. Bermes, W. Henckmann, H. LeOnardy (Hg.), Denken des Ursprungs-Ursprung des Denkens. Schelers Philosophie und ihre Anfänge in Jena (Königshausen \& Neumann, Würzburg, 1998) 149-159. 
bre puede reformar su ordo amoris fáctico y hacerlo concordar en mayor medida con su ordo amoris ideal ${ }^{17}$.

\section{EL ORDO AMORIS IDEAL}

Volvamos ahora la vista al ordo amoris ideal o normativo, al que en el citado ensayo también se denomina "determinación individual". Ya no se trata de la escala de valores por la que de hecho se orienta la vida de una persona concreta (ordo amoris descriptivo), sino de la escala por la que debería orientarse, si es que ha de ser fiel a sí misma. Dicha escala comprende, además de los valores que son accesibles a todos los hombres y que fundan normas de validez universal, un conjunto de valores que están ligados al ser espiritual de una sola persona y fundan deberes que sólo a ella atañen.

Scheler sostiene que esta doctrina del ordo amoris normativo no tiene connotaciones subjetivistas, ni autoriza al individuo a contravenir las normas válidas para todos los hombres, pues si bien existen valores que son propios de cada individuo (valores a los que él se debe), estos valores son plenamente objetivos y de hecho forman parte de la jerarquía universal de los valores, a la que la humanidad va accediendo gradualmente a lo largo de su historia. Aunque Scheler no lo dice explícitamente, podemos añadir que la novedad que representa el ordo amoris normativo de un individuo determinado nunca consiste en que el estrato último de su vida personal esté referido a una "modalidad de valor" (Wertmodalitat) hasta entonces inédita, sino en que ese individuo tiene un acceso privilegiado a ciertas cualidades de valor que, aun siendo hasta entonces desconocidas, se insertan en las modalidades conocidas por todos ${ }^{18}$. Lo que diferencia

17. Cf. Arrepentimiento y nuevo nacimiento ( $G W 5,27-59)$. Sobre este tema puede verse M. FRINGS, Der ordo amoris bei Max Scheler. Seine Beziebungen zur materialen Wertethik und zum Ressentimentbegriff, "Zeitschrift für philosophische Forschung" 20/1 (1966) 57-76.

18. Se recordará que Scheler distingue cuatro grandes modalidades axiológicas: los valores de lo agradable, los vitales, los espirituales y los de lo santo. En ocasiones añade una quinta modalidad formada por los valores de lo útil, que son los portados por las cosas que sirven instrumentalmente a la producción o conservación de bienes de la modalidad de lo agradable. Scheler parece pensar, primero, que estas 
a las personas es, por tanto, el diverso modo como van completando y enriqueciendo la estructura axiológica común a todas ellas. El ordo amoris así entendido no funda para cada hombre una moral privada, inconmensurable con la de los demás hombres, sino que especifica en cada caso de modo personal la moral común a todos ${ }^{19}$.

Sin embargo, dado que los valores que configuran el ordo amoris normativo de una persona son los responsables últimos de su identidad personal (razón por la cual Scheler denomina a ese ordo amoris determinación individual), y dado que esa identidad es irrepetible, podría objetarse que cada ser humano queda de este modo encerrado en una perspectiva axiológica que no puede compartir con ningún otro. El resultado sería una atomización de la vida moral, que quedaría fragmentada en una multiplicidad de perspectivas complementarias, sí, pero incomunicables. Con todo, no parece que esta objeción alcance a Scheler, pues aunque él sostiene que cada sujeto tiene un acceso privilegiado a los valores propios de su determinación individual, niega que se trate de un acceso exclusivo. De hecho, Scheler sostiene que, en virtud de la peculiar lucidez del amor, una persona que me ame puede conocer mi determinación individual mejor que yo mismo. Pensemos en el caso de alguien en quien el ordo amoris descriptivo y el normativo sean discrepantes. Esa persona tiene puesto su corazón en bienes que no pertenecen a las categorías axiológicas que le marca su determinación individual. Scheler se refiere a esta situación tan frecuente con el término "trastornos (Verwirrungen) del ordo amoris". Lo que ahora más importa advertir es que quien sufre un trastorno semejante padece ceguera

modalidades agotan la esfera del valor y, segundo, que todos los hombres, en tanto que seres personales, están abiertos a todas las modalidades axiológicas. De aquí se sigue que, en este nivel supremo, no cabe esperar novedades. Pero nada impide que el ordo amoris de cada individuo le haga sensible a diferencias axiológicas dentro de cada una de esas modalidades.

19. La determinación individual es distinta para cada hombre, pues de lo contrario no podría constituir el principio de individuación personal; pero todas las determinaciones individuales son congruentes, pues no son otra cosa que secciones finitas de la escala universal de los valores. En palabras del propio Scheler: "Es únicamente en el marco de la determinación universalmente válida del hombre en general (...) donde han de encontrar su lugar todas las determinaciones individuales" (GW 10, 351). 
respecto a los valores a los que está abierto el estrato más profundo de su personalidad. En el fondo no se ama a sí mismo, pues ni reconoce ni afirma cordialmente su propia determinación individual. En cambio, quien ama a una persona así es capaz de atisbar, más allá de la máscara de su ordo amoris fáctico, los valores que configuran su verdadero ordo amoris normativo, y puede ayudar a la persona amada a ser quien es.

Que la teoría del ordo amoris normativo no implica que haya un acceso exclusivo de cada sujeto a los valores propios de su determinación individual, lo confirma asimismo la teoría scheleriana del genio moral ${ }^{20}$. El genio moral es el hombre cuyo corazón está abierto a una gama de valores mucho más amplia que la conocida y compartida por los hombres de su mismo entorno cultural. Esta superior sensibilidad no la reserva el genio moral para sí mismo, sino que la comunica, muchas veces sin pretenderlo siquiera, a los hombres con los que traba relación. El genio moral es, en efecto, modelo (Vorbild) para los demás. Es capaz de ensanchar el corazón de sus semejantes, poner ante sus ojos paisajes axiológicos e ideales de vida hasta entonces ignorados. Scheler piensa que la ejemplaridad de los modelos, el influjo que ejercen sobre los demás hombres, es el principal motor del progreso del conocimiento moral de la humanidad. Esto supone, desde luego, que el ordo amoris normativo del genio moral es compartible por principio, si bien los demás hombres no accederían a los nuevos valores si éstos no estuvieran ya dados en la determinación individual del modelo. Y aunque Scheler no lo diga con estas palabras, su teoría implica sin duda que todos los hombres son algo así como genios morales en potencia, aunque a pequeña escala. No en el sentido de que todos los hombres sean moralmente excelentes, pues ya sabemos que son muy frecuentes los trastornos del ordo amoris que impiden al hombre cumplir su determinación individual, sino en el sentido de que cada hombre, en tanto que ser personal, está abierto a una constelación de valores que, por modesta que sea, representa una novedad absoluta en la historia de la humanidad. El hombre que verdaderamente se ame a sí mismo, co-

20. Cf. $G W 2,558-568 ; 10,255-344$. 
nocerá esos valores y podrá compartirlos con otros; pero también el hombre que no se ama a sí mismo cumple una función decisiva, pues por el mero hecho de existir y ser quien es brinda a quienes le aman la posibilidad de acceder a los valores que configuran su determinación individual y que él ignora. Podemos decir, generalizando, que todo acceso al mundo de los valores está condicionado por un previo ordo amoris normativo que se abre a esos mismos valores, sea en el hombre ejemplar, sea en el hombre corriente; y que la posibilidad de compartir los valores descubiertos pasa por que se ame a la persona en cuya determinación individual están inscritos originariamente. El amor es aquí el pionero, el descubridor.

Hay, con todo, una diferencia importante entre los valores descubiertos por el genio moral y los que están inscritos en la determinación individual del hombre corriente. Mientras los valores descubiertos por el genio fundan normas vinculantes para toda la humanidad, los que dan su perfil propio al hombre corriente sólo a él le obligan. Jesús, Sócrates o el Buda propusieron ideales morales que desde entonces no han dejado de interpelar a hombres de todas las épocas. Quien reproduce en su corazón el amor de estos hombres extraordinarios, sabe que está llamado a vivir a la altura de esos ideales. En cambio, quien merced a la lucidez del amor interpersonal accede a la determinación individual de una persona corriente reconoce los valores que han de orientar la vida de la persona amada, pero no por ello cree deber someterse a los mismos criterios axiológicos que ella. Si descubro, por ejemplo, en un amigo un profundo amor a la música, amor que quizá se ve estorbado por otras aficiones más superficiales, o asfixiado por un ambiente adverso que no le deja crecer, entonces le ayudaré a reconocer el objeto de su amor, pero de ningún modo me sentiré obligado a convertirme también yo en músico. Scheler sostiene, de acuerdo con esto, que la determinación individual funda para cada persona deberes no universalizables. En estos deberes consiste la particular "misión" (Aufgabe) o tarea moral de cada individuo, su "vocación (Beruf) en el antiguo sentido etimológico de la palabra" 21 .

21. $G W 10,351$. 
ESENCIA INDIVIDUAL DE VALOR Y DEBERES INDIVIDUALES

Es en la sección sexta de Formalismo donde Scheler trata de manera más precisa y completa la naturaleza de eso que venimos denominando ordo amoris normativo o determinación individual ${ }^{22}$. Si bien la teoría propuesta en esas páginas coincide en lo esencial con la presentada en el ensayo "Ordo amoris", se aprecia ahora un claro intento de insertar la idea de determinación individual en el contexto de la novedosa y compleja teoría de la persona elaborada por Scheler en Formalismo. Por otra parte, la nueva presentación de la teoría del ordo amoris normativo está condicionada por la polémica contra la ética kantiana que recorre y articula esa obra.

Como ya señalamos, Scheler renuncia ahora a las expresiones "ordo amoris normativo" y "determinación individual", que son reemplazadas por "esencia individual de valor" (individuelles Wertwesen). Esta opción terminológica puede sorprender de entrada, pues estamos habituados a pensar que toda esencia es, por definición, universal. La esencia "hombre" que encontramos dada en un individuo concreto no es poseída por ese individuo de manera exclusiva, sino que la encontramos asimismo en los demás miembros de la especie humana. Precisamente por ser predicable indistintamente de una multitud de individuos, sostenemos que esa esencia es universal: es una y la misma respecto de todos ellos. Scheler, por su parte, no niega que existan esencias universales, sino que afirma que, además de éstas, existen también esencias individuales. Todos los hombres participamos de la esencia universal "hombre", pero ocurre además que en cada hombre esa esencia universal se contrae en una esencia individual que hace de él este individuo determinado y lo distingue de cualquier otro. Como ya indicamos al comienzo de este trabajo, Scheler está persuadido de que esta esencia individualizadora, responsable última de la identidad personal, está dada en el nivel espiritual del ser humano, no en los niveles psíquico y vital (esencialmente ligados al cuerpo vivido), ni menos en la materia de que está hecho nuestro cuerpo físico.

22. Cf. $G W 2,480-486$. 
En segundo lugar, Scheler sostiene que la esencia individual de cada hombre es una esencia de valor. Ésta no es una afirmación arbitraria, sino la consecuencia que se extrae de tres tesis capitales que Scheler cree haber probado de manera independiente: primero, que la persona es una unidad de actos; segundo, que el acto básico, el que funda los demás actos de la persona, es el amor; y tercero, que la "obra" del amor, su rendimiento característico, es el acceso originario al ámbito de los valores. Según esto, la persona es fundamentalmente amor, pero no amor indiferenciado, idéntico en todos los seres personales, sino amor abierto en cada caso a una determinada constelación de valores. Esa constelación es distinta para cada sujeto personal, y esto es lo que hace de él un individuo irrepetible. Por eso tiene sentido decir que la esencia individual de la persona es precisamente una esencia de valor.

Esto supone que la esencia de valor constituye para cada hombre un ideal de perfección moral que no coincide enteramente con el de los demás hombres, toda vez que cada uno de ellos tiene una esencia distinta e irrepetible. Es éste un punto al que Scheler, siempre deseoso de mostrar las deficiencias de la ética kantiana, presta particular atención. El criterio de universalización empleado por Kant para averiguar qué máximas representan genuinas leyes morales supone, en efecto, que todos los seres racionales están sometidos a los mismos principios éticos. Todas las normas que expresan deberes serían, sin excepción posible, normas universales. Frente a este universalismo de la ética kantiana, Scheler sostiene que existen deberes estrictamente individuales, deberes que atañen a un hombre y sólo a él por estar enraizados en su esencia de valor, la cual no comparte con nadie.

La idea de que existen deberes privativos de cada persona no es del todo novedosa. Pocos años antes de que vieran la luz las páginas que Scheler le dedica, Simmel había defendido una idea semejante en un trabajo titulado "La ley individual" 23 . Pero entre ambas propuestas hay una diferencia muy sustancial. Simmel no

23. Cf. G. Simmel, Das individuelle Gesetz, "Logos" 4 (1913) 117-160. Scheler discute la propuesta de Simmel en $G W 2$, 481s. 
apela a una esencia de valor como fundamento intuitivo de los deberes no universalizables, sino que piensa que esos deberes son el dato primitivo. Ahora bien, como no cabe excluir que uno se engañe al captar sus deberes individuales, se impone preguntar por el criterio que permita distinguir un genuino deber individual de uno aparente. Dado que Simmel ignora la esencia individual de valor, tendría que contestar a esta pregunta apelando... a un principio del deber que sea universalmente válido. Está claro que Simmel no puede aceptar este modo de proceder, pues ello equivaldría a darle la razón, finalmente, a Kant, de quien pretendía distanciarse; pero no es menos claro que, al dejar sin contestar la pregunta por el criterio objetivo del deber individual, la posición de Simmel incurre en una forma de subjetivismo que podemos expresar con las palabras: esto es mi deber (y sólo mío) porque así me lo parece (a mí y sólo a mí).

Scheler, en cambio, de acuerdo con los principios fundamentales de su ética material, sostiene que todo deber se funda en un valor. Esto vale también para los deberes individuales, que se fundan en valores objetivos constitutivos de la esencia individual de una persona determinada. A esto cabría objetar que esos valores, precisamente por ser objetivos, han de fundar deberes que obliguen por igual a todos los seres racionales. Scheler sale al paso de esta objeción señalando que los valores que fundan deberes individuales se distinguen de los demás valores (es decir, de los que fundan deberes universalmente vinculantes) en que los primeros contienen una "alusión" (Hinweis) a la persona de cuya esencia individual forman parte. No sólo ocurre, por tanto, que cada persona tenga un acceso privilegiado al contenido material de su propia esencia individual, sino que también le está dada de manera intuitiva, de un modo que puede alcanzar la evidencia,

una alusión vivida a mí, un dedo índice vivido que sale de este contenido y me señala a mí; que casi dice y susurra 'para ti'. Y este contenido me asigna un lugar peculiar en el cosmos moral y, secundariamente, me ordena asimismo acciones, hechos, obras, 
todas las cuales, cuando me las represento, claman: 'soy para ti' y 'eres para mí'24.

La experiencia intuitiva descrita en este pasaje es lo que autoriza a Scheler a hablar de lo "bueno-en-sí para mí". La expresión resulta paradójica, pues solemos pensar que si algo es "bueno en sî", entonces lo es para todo el mundo y no sólo para mí; y a la inversa, cuando digo que "para mí" algo es bueno parece que estoy expresando una mera preferencia personal y que admito implícitamente la posibilidad de que otro discrepe legítimamente de mis gustos y conteste que "para él" no lo es. Por eso Scheler aclara que el "para mí" de la expresión "bueno-en-sí para mí" no comporta relativismo alguno, sino que se refiere precisamente a la alusión personal que contienen ciertos valores que me están asignados en exclusiva como parte de mi esencia individual; valores cuya realización es "buena-en-sí", pero sólo a mí atañe.

Según esto, el bien moral que puede y debe ser realizado por un hombre presenta dos aspectos distintos pero complementarios: de un lado, el que se funda en valores universalmente válidos; de otro, el que responde a valores propios de cada individuo. El cumplimiento de las exigencias que proceden de los valores universales es, según Scheler, una condición necesaria pero no suficiente para que el hombre alcance el bien más alto de que es capaz, "la salvación de la persona individual" 25 . Para alcanzar este bien es imprescindible que el hombre realice además los valores que le marca su esencia individual. Ésta es la "proporción correcta de universalismo

24. $G W 2,482$.

25. GW 2, 484. Como se ve, en las páginas de Formalismo que estamos considerando reaparece la perspectiva religiosa que ya hemos encontrado en "Ordo amoris": sólo quien vive de acuerdo con los valores que le marca su esencia individual, creada por Dios, cumple el designio divino para él y ocupa de este modo el lugar que tiene reservado en el plan salvífico de Dios (Cf. $G W 2,483$ n. 1; $G W$ 10). Pero conviene advertir que, aunque Scheler considera que su doctrina de la esencia individual de valor está en consonancia con sus propias convicciones religiosas, él presenta esa doctrina como fruto de la experiencia fenomenológica y no como doctrina revelada. Es la filosofía la que aquí ayuda a interpretar la fe religiosa, no a la inversa. 
del valor e individualismo del valor" ${ }^{26}$ que habría sido ignorada por la mayor parte de las doctrinas éticas, y de un modo paradigmático por la de Kant.

De aquí se siguen algunas consecuencias interesantes. En primer lugar, para juzgar el valor moral de una persona, para declararla buena o mala, no basta con aplicar el criterio de los valores universalmente vinculantes, sino que hemos de tener en cuenta asimismo los valores que definen su esencia individual y que sólo a ella obligan. Ahora bien, como según Scheler sólo el amor puede acceder al conocimiento de la esencia individual, se sigue que sólo el amor puede juzgar adecuadamente a los hombres. Por cierto que en la realización de esta tarea el amor puede servirse de un indicio muy elocuente: la bienaventuranza o la desesperación experimentadas por el hombre en su nivel personal; pues ocurre que esos sentimientos espirituales son reflejo fiel de la medida en que la persona realiza su esencia de valor (es decir, de la medida en que el ordo amoris descriptivo coincide con el normativo).

En segundo lugar, la doctrina de los deberes individuales permite a Scheler reivindicar la "conciencia" (Gewissen) como órgano de conocimiento moral legítimo e insustituible ${ }^{27}$. La conciencia ha sido mirada con comprensible recelo por algunas éticas universalistas, las cuales temen que, al hacer del juicio individual emitido en el fuero interno de cada sujeto una instancia última e inapelable, se esté abriendo el paso al subjetivismo y la arbitrariedad. Si se reconocen los derechos de la conciencia, el individuo dispondrá de una coartada inmejorable para rehuir el cumplimiento de las normas que a todos vinculan, pues siempre podrá alegar que él se debe a su conciencia más que a un conjunto de normas abstractas que, precisamente por ser abstractas, ignoran las peculiaridades de su caso. El resultado sería la "anarquía moral" denunciada por autores como Comte o Bentham ${ }^{28}$. Scheler, por su parte, sostiene que la posibilidad de tales abusos no debe cegarnos para el hecho evidente de

26. $G W 2,484$.

27. Cf. S. SÁNCHEZ-Migallón, La conciencia moral y la verdad personal según Max Scheler, "Pensamiento" 63 (2007) 475-486.

28. Cf. $G W 2,323$ ss. 
que la conciencia individual desempeña una función indispensable en el conocimiento moral. Recordemos que el bien que el hombre está llamado a realizar incluye una dimensión individual, ligada a la esencia de valor de cada persona. La conciencia, como órgano que accede a los deberes individuales fundados en esa esencia, es el complemento imprescindible del conocimiento de las normas que expresan deberes universales, y no puede ser reemplazada por éste. Además, no existe el peligro de que los deberes individuales alegados por la conciencia entren en conflicto con los deberes universales, pues, como sabemos, unos y otros se fundan en la escala objetiva que abraza a todos los valores.

\section{LA MATRIZ ROMÁNTICA DE LA IDEA DE ORDO AMORIS NORMATIVO}

Vista en perspectiva histórica, la teoría de la esencia individual de valor tiene sus raíces en la cultura romántica. Como ha mostrado convincentemente el filósofo canadiense Charles Taylor, uno de los aspectos principales de la reacción romántica contra las tendencias dominantes en la Ilustración consiste precisamente en la reivindicación de una dimensión estrictamente individual en la aventura moral de cada hombre ${ }^{29}$. Esta idea fue anticipada en alguna medida por Rousseau con su concepto de "sentiment de l'existence", pero su principal exponente fue Herder, quien en sus Ideas para la filosofía de la historia de la bumanidad (1784-1791) sostuvo que existe, para cada uno de nosotros, un modo peculiar y único de ser hombre, en realizar el cual consiste nuestro destino moral. "Cada hombre tiene su propia medida, por así decir un modo propio de concertarse entre sí todos sus sentimientos sensibles" ${ }^{30}$. Es responsabilidad de cada

29. Cf. Ch. TAYLOR, Hegel (Cambridge University Press, Cambridge, 1975); Hegel and Modern Society (Cambridge University Press, Cambridge, 1979); Sources of the Self (Harvard University Press, Cambridge, MA, 1992); The Ethics of Authenticity (Harvard University Press, Cambridge, MA, 1992).

30. Ideen vii.I. Obsérvese que no sólo se atribuye a cada hombre un perfil espiritual propio y dotado de fuerza normativa, sino que, al igual que en Scheler, ese factor diferencial, privativo de cada individuo, se sitúa en el nivel de los sentimientos. Por otra parte, Herder no sólo atribuye una identidad diferencial a cada ser humano, sino también a cada pueblo o nación, lo cual concuerda con la concepción 
ser humano descubrir esa medida personal a la que ha de plegar su existencia. Según esto, la vida moral consiste, al menos en una de sus dimensiones fundamentales, en ser fiel a uno mismo, huyendo tanto de una razón abstracta que impondría las mismas directrices a todos los hombres, como de la presión social que empuja al conformismo. Es a este ideal de la fidelidad a uno mismo al que Taylor se refiere con la expresión "ética de la autenticidad".

Esta concepción ha ejercido un influjo considerable en la filosofía posterior, desbordando con mucho los límites del Romanticismo alemán. Por ejemplo, a través de Humboldt llega a John Stuart Mill, quien en el capítulo segundo de su ensayo Sobre la libertad hace de ella uno de los pilares de su teoría política ${ }^{31}$. Pero el ámbito en el que el ideal de la autenticidad ha desplegado mayor influencia es el de la creación artística. A partir del giro a la subjetividad propiciado por la cultura romántica, el arte ya no perseguiría imitar a la naturaleza (es decir, un orden objetivo independiente del sujeto), sino expresar la subjetividad del artista, su peculiar forma de acceso a la realidad. La actividad creadora se entiende como investigación del yo del artista, el cual sólo se da a conocer en la acción expresiva. A este rasgo de la cultura nacida en torno a 1800 lo denomina Taylor "expresivismo". Como señala agudamente este autor, la potencia del ideal expresivista se revela en el hecho de que para buena parte de la cultura contemporánea el artista sea el modelo arquetípico de humanidad ${ }^{32}$.

Pero la ética de la autenticidad también cuenta con detractores. Numerosos críticos ven en la amplia difusión del principio de la fidelidad a uno mismo la raíz del relativismo y el narcisismo que impera en la cultura contemporánea ${ }^{33}$. So capa de vivir en consonancia con las exigencias que emanan del yo íntimo, el hombre actual se eximiría del cumplimiento de los deberes hacia sus semejantes (y hacia sí mismo) que le impone su condición racional. El giro a la

scheleriana de las identidades colectivas (Cf. GW 2, 509-548).

31. Cf. J. S. MiLl, On Liberty, cap. 2: Individuality.

32. Esto ya lo vio L. STRAUSS, Natural Right and History (University of Chicago Press, Chicago, 1953) 293.

33. C. LaSh y H. BloOM son citados en el capítulo 2 de The Ethics of Authenticity como exponentes de este tipo de crítica. 
subjetividad propiciado por el Romanticismo desembocaría de este modo en un individualismo hedonista que ve en las relaciones personales un instrumento para la satisfacción de las aspiraciones propias y debilita fatalmente el compromiso político.

Taylor, por su parte, suscribe la acusación de relativismo y narcisismo vertida contra amplios sectores de la cultura contemporánea, pero, a diferencia de otros críticos, no cree que lo certero de esa acusación justifique el rechazo del legado del Romanticismo. A su juicio, los mencionados rasgos negativos de la cultura actual no son consecuencia inevitable del ideal de la fidelidad a uno mismo, sino síntomas de la deformación de ese ideal. En su versión legítima y no deformada, que es la que Taylor intenta articular con su propuesta de una ética de la autenticidad, la fidelidad a las exigencias que emanan del yo íntimo no estaría reñida con el reconocimiento de un orden normativo externo a ese yo e independiente de él. El ideal de la autenticidad asume el giro moderno hacia la subjetividad en la medida en que reclama de todo ser humano que, en vez de someterse a los dictados de una autoridad externa, busque su propia orientación en la vida, la que está en consonancia con su identidad personal; pero esto no significa que el contenido de esa orientación haya de ser autorreferencial, limitándose a ser reflejo de mis contingentes deseos y aspiraciones. Antes bien, la ética de la autenticidad reivindica la necesidad de que cada individuo, merced a su irrenunciable perspectiva individual, acceda a un horizonte normativo que rebasa los límites de su yo. La subjetivación aquí propugnada no equivale, por tanto, a subjetivismo.

Taylor ilustra su punto de vista con una reflexión sobre la evolución del arte moderno. Hasta finales del siglo XVIII los poetas y pintores buscaron inspiración en ciertos marcos de referencia públicamente establecidos, como la historia sagrada o profana, la mitología antigua o el orden cósmico. Pero a partir de entonces y hasta nuestros días, esos marcos de referencia pierden vigencia y el artista, en vez de imitar un orden objetivo ya periclitado, se esfuerza por "reinventar" la naturaleza desde su propia óptica, presentarla tal como resuena en su propia sensibilidad. Para Taylor lo decisivo es advertir que este protagonismo de la subjetividad del artista no 
lo condena a la incomunicación y a una autorreferencialidad estéril, sino que hace posible la creación de nuevos lenguajes que nos permiten acceder a aspectos de la realidad para los que antes no teníamos palabras. Por ejemplo, los paisajes de Friedrich rompen decididamente con la iconografía tradicional y buscan en la naturaleza un simbolismo nuevo. Pero esta novedad se apoya en la convicción de que existe una afinidad secreta entre nuestros sentimientos y las escenas naturales representadas. Por tanto, no se trata simplemente de presentar una reacción subjetiva ante un paisaje, sino de descubrir dimensiones de la realidad natural que hasta entonces se hurtaban a nuestra mirada. Valiéndose de una expresión del poeta Shelley, Taylor sostiene que el arte postromántico se ha caracterizado por la creación de "lenguajes más sutiles" que nos permiten referirnos a aspectos del mundo compartido para los que no teníamos palabras. En su obra principal, Las fuentes del yo, Taylor ilustra este fenómeno con extensos y brillantes análisis de las poéticas de Rilke, Pound, Mann o Proust.

Con vistas a una justificación de la ética de la autenticidad propugnada por Taylor, lo decisivo es saber si realmente cabe establecer una analogía sustancial entre las tendencias artísticas postrománticas y el ideal específicamente moral de la fidelidad a uno mismo. Más concretamente, se trataría de mostrar convincentemente que, al prestar atención a las exigencias morales que proceden de la propia identidad personal, el sujeto no se aparta del orden moral compartido con los demás hombres. Y habría que mostrar asimismo que esa atención prestada a la voz que procede del interior de cada uno supone un enriquecimiento de la vida colectiva comparable al que aportan, en el orden cultural, los "lenguajes más sutiles" creados por los artistas. Excede de los límites del presente trabajo discutir la medida en que Taylor se ha enfrentado con éxito a esta doble tarea. Pero no queremos dejar de observar que Scheler se ha ocupado de las dos cuestiones planteadas, pues en este hecho hemos de ver una nueva confirmación de la matriz romántica de su doctrina del ordo amoris normativo. En efecto, hemos visto sostener a Scheler que el ordo amoris constitutivo de la identidad individual se orienta en cada caso a una determinada constelación de valores; como esa conste- 
lación forma parte del orden axiológico objetivo, las exigencias que proceden de ella no pueden entrar en colisión con las que proceden de los valores que son accesibles a todos los hombres y no definen, por tanto, la identidad personal de un determinado individuo. Y sabemos, por otra parte, que la teoría scheleriana de los modelos (Vorbilder) y del seguimiento (Nachfolge) explica el modo como el genio moral enriquece a la humanidad al inaugurar nuevos horizontes de valor e ideales de vida ${ }^{34}$.

34. Este trabajo ha sido realizado en el marco del Proyecto de Investigación FFI 201563794-P del Ministerio de Economía y Competitividad. 
